\title{
Commentary: Worldwide disparities in cardiac surgical care: Thinking globally not locally to solve problems of limited resources and access to specialized care
}

\author{
Victor A. Ferraris, MD, PhD, ${ }^{a}$ and A. Thomas Pezzella, $\mathrm{MD}^{\mathrm{b}}$
}

\author{
From the ${ }^{\mathrm{a}}$ University of Kentucky, Lexington, Ky; and ${ }^{\mathrm{b}}$ International Children's Heart Fund, Boca Raton, Fla. \\ Disclosures: Authors have nothing to disclose with regard to commercial support. \\ Received for publication April 24, 2019; accepted for publication April 25, 2019; available ahead of print June 5, \\ 2019. \\ Address for reprints: Victor A. Ferraris, MD, PhD, University of Kentucky, A301 Kentucky Clinic, 740 S Lime- \\ stone, Lexington, KY 40536-0284 (E-mail: ferraris@uky.edu). \\ J Thorac Cardiovasc Surg 2020;159:997-9 \\ $0022-5223 / \$ 36.00$ \\ Copyright (c) 2019 by The American Association for Thoracic Surgery \\ https://doi.org/10.1016/j.jtcvs.2019.04.070
}

Vervoort and colleagues ${ }^{1}$ map out the breadth and depth (or lack thereof) of access to cardiac surgical care throughout the world. ${ }^{1}$ They identified the world's cardiac surgery workforce based on cardiac surgeons registered with the Cardiothoracic Surgery Network (CTSNet). The world's cardiac surgery workforce was divided into 4 groups based on World Bank income groups: low-income countries, lower-middle-income countries, upper-middle-income countries, and high-income countries. Within the geographic areas included in the income groups they assigned the number of cardiac surgeons registered with CTSNet who listed their base of practice as being in 1 of the 4 income groups listed by the World Bank. The authors hope that knowing the availability of cardiac surgery support in various regions will allow for targeted policy interventions that may improve the gap in care for a large segment of the world's population. There were obvious arbitrary assumptions made to create this study and it is likely that these assumptions lead to some inaccuracies. ${ }^{2}$ However, it is doubtful that these inaccuracies detract from the authors' message.

The authors found that there is a 100 -fold difference between the number of cardiac surgeons who practice in highincome countries and those who practice in low-income countries. These disparities are by no means strictly based on geography. Large disparities in cardiac surgery care were found between neighboring adjacent countries and these locoregional disparities have already been recognized. ${ }^{3,4}$ It is impossible to challenge the authors' premise that there are significant worldwide disparities in the care of patients requiring cardiac surgery. It only takes a visit to a hospital in a resource-limited country to understand that patients are dying from totally treatable cardiac diseases.

The types of treatable diseases in resource-limited countries are not seen to the same extent in developed countries. Rheumatic heart disease is virtually unrecognizable in

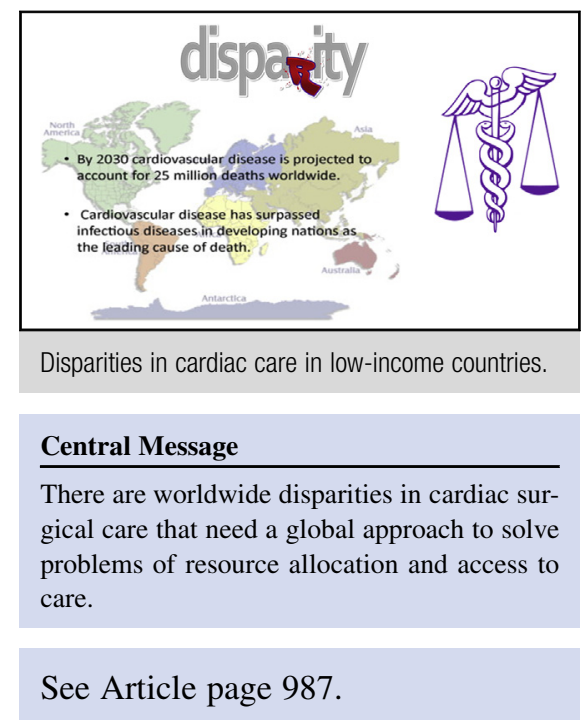

North America but is an extremely common cause of childhood mortality in Central Africa, for example. ${ }^{5}$ Disease disparities challenge efforts at training cardiac surgeons to practice in resource-limited countries and regions. Further, cardiac surgery infrastructure and resources are compromised in resource-limited countries. Problems like heart valve unavailability, limited perfusion techniques, and inadequate diagnosis and treatment of typical complications like atrial fibrillation cause suboptimal surgical results judged by modern standards. ${ }^{6,7}$ Relatively simple things like pericardial effusions present life-threatening difficulties in diagnosis and treatment in resource-limited countries. ${ }^{8}$ Disparities in cardiac disease management in low-income countries are particularly critical in the treatment of cardiac disease in neonates and infants.

It is a simple exercise to spell out these disparities in care in low- and lower-middle- income countries. What is not simple is describing solutions to this obvious problem. In an American Association for Thoracic Surgery presidential address in 2001, Jim Cox called for action to reduce worldwide inequalities in cardiac surgical care: ${ }^{10}$

We cannot continue to boast about the number of cases we do, as if increased volumes somehow bestow increased virtue, when we alone have the ability to add 75 years onto the lives of millions of children and yet choose not to do so. 
TABLE 1. Ingredients for enhancements in global cardiac surgery

\begin{tabular}{lc}
\hline \multicolumn{1}{c}{ Need } & Potential solution \\
\hline Full-time surgeons trained to manage diseases unique to areas in need & $\begin{array}{c}\text { Surgical training programs with expertise in unique cardiac diseases of } \\
\text { underserved areas (eg, rheumatic heart disease, and congenital heart } \\
\text { disease) }\end{array}$ \\
$\begin{array}{c}\text { Trained support staff (eg, operating room support staff, cardiologists, } \\
\text { perfusionists, intensive care, and anesthesia) }\end{array}$ & $\begin{array}{c}\text { Training programs for support staff willing to have graduates placed in } \\
\text { underresourced areas }\end{array}$ \\
$\begin{array}{c}\text { Construction and development of advanced care needs, including } \\
\text { operating rooms, intensive care units, and cath labs }\end{array}$ & $\begin{array}{c}\text { Funding from all available sources (eg, government, charitable, and self- } \\
\text { pay) }\end{array}$ \\
$\begin{array}{c}\text { Safe medical environment with conflict-free protected areas for patients, } \\
\text { families, and medical staff }\end{array}$ & $\begin{array}{c}\text { Government-enforced conflict free zones, possibly with help from } \\
\text { nongovernmental organizations and/or the United Nations }\end{array}$ \\
$\begin{array}{c}\text { Established well-trained primary care referral patterns } \\
\text { Infrastructure needs for transport and housing of patients to regional } \\
\text { medical facilities that provide safe and competent cardiac surgery } \\
\text { care }\end{array}$ & $\begin{array}{c}\text { Training programs for recognition and triage of patients with cardiac } \\
\text { surgery needs }\end{array}$ \\
$\begin{array}{c}\text { Build a research infrastructure to address problems and questions unique } \\
\text { to under-resourced areas in need of cardiac surgery facilities } \\
\text { get to regional centers and to have a safe family living space near } \\
\text { hospital }\end{array}$ & $\begin{array}{c}\text { Establish a charitable funding organization to facilitate research into } \\
\text { development of solutions to problems that are unique to underserved } \\
\text { and under-resourced areas }\end{array}$ \\
\hline $\begin{array}{l}\text { Grassroots approach supported by global trainees and organizations to } \\
\text { develop local programs that recognize the unique needs of different } \\
\text { regions }\end{array}$ & $\begin{array}{c}\text { Development of unique local organizations that can be counted on to } \\
\text { facilitate and enhance programmatic development of regional cardiac } \\
\text { surgical programs (eg, The International Student Surgical Network) }\end{array}$ \\
\hline
\end{tabular}

The sad truth is that huge gaps in care between developed and resource limited countries still remain. Granted, in the poorest countries, where access to drinking water and basic nutrition is problematic, it may be more appropriate to focus on those issues first, rather than on cardiac surgery. ${ }^{11}$ Nonetheless, there is an enormous population at risk for cardiac disease-something like 4 billion people. This population far overshadows the population that stands to benefit from cardiac surgery in developed countries. Estimates suggest that $80 \%$ of the world's treatable cardiac disease exists in developing countries where cardiac surgery care is limited. ${ }^{12,13}$ This prevalence of treatable cardiac disease in underresourced areas appears to be consistent over more than 25 years, and is likely to increase as better control of infectious disease and public health initiatives improve worldwide. ${ }^{14}$

What can be done about these gaps in care? Is the problem hopeless, or are there solutions on the horizon? At present, solutions appear to be mostly local efforts in selected regions, rather than global approaches with widespread efforts using evidence-based interventions. An essential starting point is a data repository of international resources and organizations that may be helpful to begin global approaches to cardiac surgery care. Creation of an international database that encompasses multiple organizations and provides for pooling of resources in key areas of need might allow for more rapid resource allocation. A partial list of these organizations might include

\section{- CTSNet;}

- Professional societies with a focus on medically underserved areas;

- Corporate entities with interests in specific underserved areas;

- Nongovernmental organizations that operate independently of any government (eg, Junior Chamber International, local-level organizations that organize conferences, self-help projects, and publications);

- Local governments that can provide support for finances, infrastructure, and protection; and the

- World Health Organization of the United Nations.

Unfortunately, there is not an overarching mechanism for a solution to the various and complex needs of individual countries. As Vervoort and colleagues point out, ${ }^{1}$ there are 77 nonprofit, nongovernmental organizations that have attempted to provide some cardiac surgery care in low- to low-middle income groups. A unified approach that includes these organizations, perhaps with an overarching, more global administrative structure, could allocate needed resources to specific areas, especially in times of extreme need created by famine, natural disaster, warfare, or disease outbreak. A list of global needs for providing stable cardiac surgical care is easy to create (Table 1). The elements listed in Table 1 are present in developed countries, but scarce to nonexistent in developing countries.

Global approaches to cardiac surgery care that include the elements listed in Table 1 are not undertaken in any organized fashion. The need for a global approach to 
cardiac surgery care in underserved areas seems obvious. There are people and organizations willing to help. What seems to be missing is an organized approach that understands the needs and is capable of allocating assets to the underresourced low-income countries. Vervoort and colleagues ${ }^{1}$ provide a good starting point by highlighting needs. We look forward to future efforts in this area.

\section{References}

1. Vervoort D, Meuris B, Meyns B, Verbrugghe P. Global cardiac surgery: access to cardiac surgical care around the world. J Thorac Cardiovasc Surg. 2020;159:987-96.e6.

2. Mozaffarian D. Global scourge of cardiovascular disease: time for health care systems reform and precision population health. J Am Coll Cardiol. 2017;70:26-8.

3. Forcillo J, Watkins DA, Brooks A, Hugo-Hamman C, Chikoya L, Oketcho M, et al. Making cardiac surgery feasible in African countries: experience from Namibia, Uganda, and Zambia. J Thorac Cardiovasc Surg. 2019;158:1384-93.

4. Ferraris VA, Pezzella AT. Commentary: scratching the surface of sustainable cardiac surgery in sub-Saharan Africa: a voice that needs to be heard. J Thorac Cardiovasc Surg. January 26, 2019 [Epub ahead of print].

5. Cilliers AM. Rheumatic fever and rheumatic heart disease in Gauteng on the decline: experience at Chris Hani Baragwanath Academic Hospital, Johannesburg, South Africa. S Afr Med J. 2014;104:632-4.
6. Khan MF, Khan MS, Bawany FI, et al. Predictors of mortality in patients undergoing mitral valve replacement. Glob J Health Sci. 2015;8:37-42.

7. Assy J, Skouri H, Charafeddine L, Majdalani M, Younes K, Bulbul Z, et al. Establishing an ECMO program in a developing country: challenges and lessons learned. Perfusion. 2019. 267659119834489.

8. Imazio M, Adler Y. Management of pericardial effusion. Eur Heart J. 2013;34: 1186-97.

9. Kinsley RH. The third Aldo Castaneda lecture: the neglect of neonatal/infant cardiac disease in Africa-continental genocide? World J Pediatr Congenit Hear Surg. 2012;3:241-3.

10. Cox JL. Presidential address: changing boundaries. J Thorac Cardiovasc Surg. 2001;122:413-8.

11. Fenton KN, Cardarelli M, Molloy F, Novick WM. Ethics in humanitarian efforts: when should resources be allocated to paediatric heart surgery? Cardiol Young 2019;29:36-9.

12. Murray CJ, Lopez AD. Evidence-based health policy-lessons from the global burden of disease study. Science. 1996;274:740-3.

13. Oliveira GB, Avezum A, Roever L. Cardiovascular disease burden: evolving knowledge of risk factors in myocardial infarction and stroke through population-based research and perspectives in global prevention. Front Cardiovasc Med. 2015;2:32.

14. Shepard D, VanderZanden A, Moran A, Naghavi M, Murray C, Roth G. Ischemic heart disease worldwide, 1990 to 2013: estimates from the global burden of disease study 2013. Circ Cardiovasc Qual Outcomes. 2015;8:455-6.

15. Vervoort D, Bentounsi Z. InciSioN: developing the future generation of global surgeons. J Surg Educ. 2019;76:1030-3. 